[running head]Kapilashrami et al.: Migration health research in south and south-east Asia

\section{Migration health research and policy in south and south- east Asia: mapping the gaps and advancing a collaborative agenda}

Anuj Kapilashrami ${ }^{1}$, Kolitha Wickramage ${ }^{2}$, Nima Asgari-Jirhandeh ${ }^{3}$, Anns Issac ${ }^{3}$, Anjali Borharde ${ }^{4}$, Ganesh Gurung ${ }^{5}$, Jeevan $R$ Sharma ${ }^{6}$ on behalf of the MiHSA Steering Group

${ }^{1}$ University of Essex, Colchester UK, ${ }^{2}$ International Organization for Migration, Manila, Philippines, ${ }^{3}$ Asia Pacific Observatory on Health Systems and Policies, World Health Organization Regional Office for South-East Asia, New Delhi, India, ${ }^{4}$ Disha Foundation, Gurugram, Haryana, India, ${ }^{5}$ Nepal Institute of Development Studies, Kathmandu, Nepal, ${ }^{6}$ University of Edinburgh, Edinburgh, UK

Correspondence to: Dr Anuj Kapilashrami (a.kapilashrami@essex.ac.uk)

Commented [KA1]: Acknowledgements: (SG members
who are not co-authors)
M Sivakami, Tata Institute of Social Scinces, Mumbai, India
S. Irudaya Rajan, Centre for Development Studies, Kerala,
India
Shabnum Sarfraz, Visiting Scientist, Harvard T H Chan School
of Public Health
Roomi Aziz, Pathways2Impact, Pakistan
Ekatha John, Independent Researcher \& Journalist, India

\begin{abstract}
Migrant health has been the subject of various international agreements in recent years. In parallel, there has been a growth in academic research in this area. However, this increase in focus at international level has not necessarily strengthened the capacity to drive evidence-informed national policy and action in many low- and middle-income countries. The Migration Health South Asia (MiHSA) network aims to challenge some of the barriers to progress in the region. Examples include the bias towards institutions in high-income countries for research funding and agendasetting and the overall lack of policy-focused research in the region. MiHSA will engage researchers, funders and policy-makers in collectively identifying the most pressing, yet feasible, research questions that could help strengthen migrant and refugee health relevant to the region's national contexts. In addition, policies and provisions for different migrant populations in the region will be reviewed from the health and rights perspectives, to identify opportunities to strategically align research agendas with the questions being asked by policy-makers. The convergence of migration policy with other areas such as health and labour at global level has created a growing imperative for policy-makers in the region to engage in cross-sector dialogue to align priorities and coordinate responses. Such responses must go beyond narrow public health interventions, and embrace rights-based approaches to address the complex patterns of migration in the region, as well as migrants' precarity, vulnerabilities and agency.
\end{abstract}

\title{
Background
}

Migration is a global phenomenon. Alongside the significant benefits migration offers to individuals, societies, states and economies, it also presents critical public policy, humanitarian and human rights challenges. The health and well-being of migrants and refugees is a public policy issue and an emergent field of scholarship and advocacy. Migrant health has been the subject of various international consultations and agreements in recent years, such as the Global compact for safe, orderly and regular migration ${ }^{1}$ and the Global compact on refugees in $2018 .^{2}$ In parallel, there has been a growth in academic research on the health aspects of migration. Despite this increase in focus at international level, the capacity and opportunities to drive evidence-informed national policy and action on migration and health remains limited in many low- and middle-income countries. ${ }^{3}$ Clearly, migrant health will need to be more firmly embedded in national agendas if the overarching aims of global initiatives are to be realized, not least the call of the 2030 Agenda for Sustainable Development to "leave no one behind" ${ }^{4,5}$

The need to bring together the migration and health research and policy communities was the catalyst for the establishment of the Migration Health South Asia (MiHSA) network in 2019. ${ }^{6}$ MiHSA evolved during a series of 
consultations, seminars and policy dialogues held during 2018-2019 in Bangladesh, India, Malaysia and Nepal. MiHSA's activities focus on countries in Southern Asia, a loosely defined geographical scope to include both South Asian and South-East Asian countries. These consultations brought together local, regional and international institutions to reflect on the current gaps in knowledge on migration and health in south and south-east Asia and to explore pathways for building communities of knowledge and practice. The objectives were twofold: first, to engage academic scholars, nongovernmental organizations and advocacy groups to collectively assess the evidence base and identify the main gaps in knowledge; second, to engage key policy stakeholders to assess the utility of current research outputs and identify their key evidence requirements for improved policy-making.

In this paper, we synthesize key lessons learnt to date and identify core values and priorities to advance a collaborative agenda that can shape future research and practice to improve migration, health and rights in south and south-east Asia.

\section{What do we know - and what are the gaps?}

\section{Quantifying the bias in what is researched, and by whom}

The production and use of knowledge or evidence on migration is entrenched in gross global inequities. Research funding, agenda-setting and practice disproportionately favour institutions in high-income countries. A bibliometric analysis of global migration health research papers published during 2000-2016 in the peer-reviewed literature revealed that the vast majority of articles on migration were authored by research institutions in high-income migrant destination countries. ${ }^{7}$ The analysis also showed that the research output on migrant health from Asia was relatively low, despite the region having "the most dense international migration corridors and the largest numbers of international migrants whose country of origin is in Asia". ${ }^{7}$ In addition, analyses limited to the formal research literature largely fail to capture the insights of the civil society organizations that work closely with migrants and displaced populations. These groups have limited access to funding and publish their findings in less formal outlets, such as reports and briefs, that may not be captured by systematic reviews and bibliometric analysis.

As noted in the International Organization for Migration's 2020 annual report, more sustained effort is needed to support research institutions and researchers in low- and middle-income settings, including by confronting some structural impediments to gaining funding and building capacity. ${ }^{8}$ Part of MiHSA's role will be to examine the power inequalities in international knowledge networks and aim to rebalance them by creating and sharing new opportunities via collaborative research, writing and joint webinars for more knowledge generation and leadership situated in south and south-east Asia.

\section{Addressing the lack of prioritization in the region}

Migration health continues to be a relatively underexplored topic within south and south-east Asia, with limited attention given to the health and social care needs of migrants, who are a highly transient, diverse and heterogeneous population group, or to the peculiarities of the geopolitical context of the region. For example, the health of internal migrants in the region is poorly understood, despite their high numbers. The Global report on internal displacement 2020 estimated that south Asia experienced 30\% of the world's internal displacement in 2019, mostly triggered by population exposure to disasters including floods and droughts, as well as to unresolved conflicts and violence. ${ }^{9}$ There were 5 million new disaster displacements in India alone in 2019, the highest number in any country in the world, resulting from factors such as increasing hazard intensity, high population exposure and high levels of social and economic vulnerability.

sub-set analysis of the bibliometric analysis of the global migration health literature [*] by one of the authors (KW) for South and South-east Asia indicated a disproportionate focus towards research on infectious diseases, mental health (by health themes) and on undocumented migrants and refugees (by migrant categories). MiHSA is supporting researchers in the region to build on this work using robust bibliometric analysis to more fully understand the gaps in published and unpublished research. In addition, the broader context of migration and the conditions in which migrants work and live shape their health and well-being. Yet insufficient attention has been given to studying the role of structural inequalities in determining low-income migrants' poor access to health care and vulnerability

Commented [KA2]: *: Sweileh, W.M., Wickramage, K. Pottie, K., Hui, C., Roberts, B., Sawalha, A.F. and Zyoud, S.H., 2018. Bibliometric analysis of global migration health research in peer-reviewed literature (2000-2016). BMC public health, 18(1), p.777. 
to ill health. ${ }^{10}$ Analysis of vulnerability and agency across different stages of people's mobility and settlement is critical to inform inclusive and effective policies and institutional responses. ${ }^{5,11,12}$ Research in south and south-east Asia therefore needs to capture not only the factors that place migrants at risk but also those that facilitate thriving and resilience. Such focus is core to MiHSA's capacity building workshops in the region that provide early career scholars the necessary conceptual and methodological skills and insights in undertaking research in this field, and emphasise the intersections of gender and other social inequalities in such research.

\section{Unlocking the capacity to identify feasible, impactful research}

Migration health research globally is characterized by glaring methodological and data gaps, and thus this is also the case for South Asia. There continues to be a lack of disaggregated baseline information on migrants based on factors such as their gender, livelihood, religion and ethnicity. The omission is particularly striking for internal migrants as these factors determine different needs of different migrant populations across socio-economic contexts. This dearth of information hampers effective policy development and may even undermine the impact of any actions taken. With respect to design, research in this area is dominated by cross-sectional studies, which cannot take account of the temporal and spatial dimensions of mobility and the circularity of migration that is characteristic of the south and south-east Asian context. With respect to focus, there is a need for more operational research on neglected topics including remittances and their utilization for nutrition and food security, and portability of social protection, health and welfare schemes.

MiHSA recognizes the need for (i) country-level mapping of existing sources of data such as the national Demographic and Health Surveys and sources compiled by non-government initiatives, (ii) identifying gaps in evidence and (iii) more targeted commissioning of research in key priority areas. In parallel, building the capacities of local research institutions to advance more in-depth research on experiences and outcomes is essential. This exercise is currently under way, and involves identifying and defining research priorities using the Child Health and Nutrition Research Initiative approach to research priority setting. ${ }^{13}$ This brings together funders, researchers and policy-makers in deciding the most pressing yet feasible research questions that could help strengthen migrant and refugee health in national contexts in south and south-east Asia.

\section{Engaging in researcher-policy-maker collaboration from the outset}

A stark disconnect exists between the production of knowledge by researchers and its use by policy-makers. On the one hand, the rich information and analysis produced by researchers may not be synthesized in a way that is accessible to policy-makers. Researchers often tend to see policy-makers as a community to engage with after findings are generated and published, rather than as potential collaborators. On the other hand, policy-makers may be unaware of the benefits of consultation with migration scholars, advocates or practitioners in the development of national policy processes. Whatever the reasons, the lack of perspective on migrant health in national task forces and policy work results in important omissions. For example, a review of the pandemic influenza preparedness plans in place in 21 countries of the Asia Pacific region in 2016 found that only three countries - Maldives, Papua New Guinea and Thailand - identified at least one migrant group in their national plan. ${ }^{14}$

Tackling the knowledge-policy gap prompted intersectoral working being adopted as a core principle in the work and mandate of the MiHSA network, with an emphasis on prioritizing engaging with policy actors at every stage. Rather than taking an instrumental role in linking research and policy, MiHSA seeks to enable researchers, policymakers and other stakeholders to collaborate on defining the analyses needed to design effective responses. This approach requires researchers to be alert to political and policy opportunities that might arise and to respond with evidence on critical issues. To address health issues and determinants stemming from various migration flows, a whole-of-government approach was adopted by Sri Lanka to advance the National Migration Health Policy and an interministerial action plan. ${ }^{15}$ This was guided in large part by the evidence generated through a national research agenda commissioned by the Ministry of Health with technical cooperation from the International Organization for Migration. Health risks and their consequences were identified through rigorous research, and policy was then developed based on the evidence generated. The collaborative approach used by Sri Lanka offers important insights 
into how health policy-makers, local researchers and civil society can meaningfully work together in driving a research agenda that leads to national policy-making and priority-setting on migration and health. ${ }^{15}$

\section{Addressing the broader structural impediments to progress}

Despite migration being a major issue for many south and south-east Asian countries, migrants are not prioritized in policies and resource allocation. Benefits could accrue from greater cooperation among countries, and states within countries, from improvements in bilateral relations on mobility and from political commitment to universalize health and social care and allow its portability. At global level, the two disciplines of health governance and migration are beginning to converge. However, at national level, policies continue to be developed in silos such as immigration, humanitarian aid, security, labour and public health, which can have distinct and often conflicting goals. ${ }^{16} \mathrm{~A}$ central challenge to developing an integrated agenda for migration and health is that the driver for examining this interface is not migrants' health needs; rather, it is preservation of population health by containing disease outbreaks that are often associated with migrant populations. Such focus counters any attempts to redress violations around health and wellbeing of migrants that are evident in current health policy initiatives.

Despite these challenges, there are certain enablers and emerging local initiatives that could inform integrated national- and regional-level action, such as initiatives to support tribal migrants in certain states in India. ${ }^{17}$ and more recent targeting of social protection measures at migrants in the wake of COVID-19.

An important planned initiative is for MiHSA to map policies and provisions for different migrant populations in south and south-east Asia and to review them from health and rights perspectives. This analysis should help to identify opportunities to strategically align research agendas with the questions being asked by policy-makers, as well as the intersections at which action to advance an integrated agenda can take place.

\section{Conclusion}

The convergence of migration policy with other areas such as health and labour at global level has created a growing imperative for policy-makers in south and south-east Asia to engage in cross-sector dialogue to align priorities and coordinate responses to migration. Such responses must go beyond narrow public health interventions, and embrace rights-based approaches to address the complexities of circular migration in the region, as well as migrants' precarity, vulnerabilities and agency. At the heart of this ambitious agenda must lie a vibrant research community of scholars and practitioners who are equipped with appropriate skills and opportunities to engage with diverse communities and voices. Just as policy-makers need to work across sectors, researchers need to bridge the gulf between the two ecosystems of migration research and health policy and systems research.Error! Bookmark not defined. Through developing and supporting these synergies, MiHSA aims to support a transformative agenda for improving migrants' health and lives.

Source of support: The workshops and consultations were held with funding support from the British Council.

Conflict of interest: Nima Asgari-Jirhandeh and Anns Issac are employees of the World Health Organization (WHO) and Kolitha Wickramage of the United Nations Migration Agency. The opinions expressed are those of the authors and do not necessarily reflect the views of the International Organization for Migration (IOM) and the Asia Pacific Observatory on Health Systems and Policies (APO).

Authorship: All authors contributed to the discussion and analysis reported in this article and approved the final version of the manuscript. AK conceptualized the paper and wrote the first draft with inputs from KW and JS. NAJ, Al, AB and GG reviewed and contributed to the paper.

How to cite this paper: Kapilashrami A, Wickramage K, Asgari-Jirhandeh N, Issac A, Borharde A, Gurung G, Sharma J. Migration health research and policy in south and south-east Asia: mapping the gaps and advancing a collaborative agenda. WHO SouthEast Asia J Public Health. 2020;9(2):xx-xx. doi:10.4103/2224-3151.xxxxxx.

\section{References}

Commented [SR3]: Author: I removed "internal" from this sentence because the following text seems to be about mobility between countries. Global compact etc. Reviewer noted it was confusing. 
${ }^{1}$ International Organization for Migration. Global compact for migration (https://www.iom.int/global-compact-migration, accessed 23 July 2020).

2 Office of the United Nations High Commissioner for Refugees. The global compact on refugees (https://www.unhcr.org/uk/the-global-compact-on-refugees.html, accessed 23 July 2020).

${ }^{3}$ Wickramage K, Annunziata G. Advancing health in migration governance, and migration in health governance. Lancet. 2018 Dec;392(10164):2528-30. https://doi.org/10.1016/S0140-6736(18)32855-1 PMID:30528473

${ }^{4}$ Transforming our world: the 2030 Agenda for Sustainable Development. New York: United Nations; 2015 (A/RES/70/1; https://sustainabledevelopment.un.org/content/documents/21252030\%20Agenda\%20for\%20Sustainable\%20Development $\% 20$ web.pdf, accessed 23 July 2020).

${ }^{5}$ Health of migrants: resetting the agenda - report of the 2nd Global Consultation, Colombo, Sri Lanka, 21-23 February 2017. Geneva: International Organization for Migration; 2017 (https://www.iom.int/sites/default/files/our work/DMM/MigrationHealth/GC2_SriLanka_Report_2017_FINAL_22.09.2017_Internet.pdf, accessed 31 July 2020).

${ }^{6}$ Migration Health South Asia (MiHSA) network (https://mihsa.org/, accessed 29 July 2020).

${ }^{7}$ Sweileh WM, Wickramage K, Pottie K, Hui C, Roberts B, Sawalha AF, et al. Bibliometric analysis of global migration health research in peer-reviewed literature (2000-2016). BMC Public Health. 2018 Jun;18(1):777. https://doi.org/10.1186/s12889-0185689-x PMID:29925353

${ }^{8}$ World migration report 2020. Geneva: International Organization for Migration; 2020 (https://www.un.org/sites/un2.un.org/files/wmr 2020.pdf, 28 July 2020).

${ }^{9}$ Global report on internal displacement 2020. Geneva: Internal Displacement Monitoring Centre, Norwegian Refugee Council; 2020 (https://www.internal-displacement.org/sites/default/files/publications/documents/2020-IDMC-GRID.pdf, accessed 31 July 2020).

${ }^{10}$ Kusuma YS, Babu BV. Migration and health: a systematic review on health and health care of internal migrants in India. Int J Health Plann Manage. 2018 Oct;33(4):775-93. https://doi.org/10.1002/hpm.2570 PMID:30074640

${ }^{11}$ Kapilashrami A, Hankivsky O. Intersectionality and why it matters to global health. Lancet. 2018 Jun;391(10140):2589-91 https://doi.org/10.1016/S0140-6736(18)31431-4 PMID:30070211

${ }^{12}$ Wickramage K, Vearey J, Zwi AB, Robinson C, Knipper M. Migration and health: a global public health research priority. BMC Public Health. 2018 Aug;18(1):987. https://doi.org/10.1186/s12889-018-5932-5 PMID:30089475

${ }^{13}$ Rudan I, Gibson JL, Ameratunga S, El Arifeen S, Bhutta ZA, Black M, et al.; Child Health and Nutrition Research Initiative. Setting priorities in global child health research investments: guidelines for implementation of CHNRI method. Croat Med J. 2008 Dec;49(6):720-33. https://doi.org/10.3325/cmj.2008.49.720 PMID:19090596

${ }^{14}$ Wickramage K, Gostin LO, Friedman E, Prakongsai P, Suphanchaimat R, Hui C, et al. Missing: where are the migrants in pandemic influenza preparedness plans? Health Hum Rights. 2018 Jun;20(1):251-8. PMID:30008567

${ }^{15}$ Migration health research to advance evidence based policy and practice in Sri Lanka. Makati City, the Philippines: Migration Health Research Unit, International Organization for Migration; 2017 (https://publications.iom.int/books/migration-healthresearch-advance-evidence-based-policy-and-practice-sri-lanka, accessed 31 July 2020).

${ }^{16}$ Zimmerman C, Kiss L, Hossain M. Migration and health: a framework for 21st century policy-making. PLoS Med. 2011 May;8(5):e1001034. https://doi.org/10.1371/journal.pmed.1001034 PMID:21629681

${ }^{17}$ Disha Foundation. New Delhi: Tribal Research Institute, Ministry of Tribal Affairs; 2019 (http://www.dishafoundation.ngo/projects/research-pdf/PolicyBriefReport-TribalMigrationResearch.pdf, accessed 31 July 2020). 